\title{
Infrastructure to support the digital economy in Chile
}

Rossella Cominetti C.

Former head of the Economic Regulation Department, Office of the Undersecretary for Telecommunications (SUBTEL), Ministry of Transport and Telecommunications, Chile rcominetti@indap.cl.
This article presents a model for dealing systematically with the different matters associated with policies for developing the infrastructure necessary to support a digital economy, identifying the roles of the State and the private sector in this respect. It also describes the main initiatives taken in terms of creating and improving the infrastructure and content in the case of Chile, which illustrates the recent progress made in developing the country's digital economy and the challenges still pending in this field. There is general agreement that Chile must move closer to those countries already incorporated into the information society, and it must do so quickly and promptly. This study helps to identify the main factors for evaluating the policy aimed at promoting access to the digital economy, which is one of the central pillars for designing policies to advance toward the information society. 


\section{I}

\section{Introduction}

The origination of a new model in the telecommunications industry, arising from the digitisation of signals and the development of the Internet, has set the stage for a radical transformation of economic and social relations on a more efficient and democratic basis which will improve competitiveness, participation and equality. In particular, the replacement of traditional mechanisms for carrying out transactions, administrative procedures and communications in general with methods that make intensive use of information technologies is giving rise to what has been called the "new digital economy", whose benefits in terms of productivity make it necessary to include the economic agents in this network promptly and massively. At the same time, the externalities and opportunities in terms of human capital associated with access to and use of the new technologies pose various challenges to public policy.

There is a general consensus that a tardy involvement in these information and communications technologies would not only mean missing out on many of the opportunities offered by access to information -larger markets, lower production costs, better trainingbut also a possible decline in the position achieved by the traditional economy. In this sense, information technology has become a decisive factor in economic growth, and its insufficient development can cause a widening of the gap with respect to countries that enter the digital economy more quickly. At the national level, massive access by the population to the Internet can help to reduce inequalities that limit equitable access to the benefits of economic growth.

Faced with this new phenomenon, it is essential to speed up the expansion of access to and use of the Internet as a tool for information, transactions, administrative procedures and the provision of social services (for example, education and health care) and thus build a non-exclusive pattern of sustained growth that helps to improve the quality of life of all citizens. In order to do this, it is essential to coordinate the efforts of the different actors involved, that is to say, the State, companies, content providers, universities, nongovernmental organizations and the community itself.

In the development of information infrastructure, the main task of the State is to create a system of incentives to ensure both appropriate levels of access to the networks and the provision of suitable content. To this end, the authorities should:

- Promote universal access to the Internet.

- Eliminate barriers that interfere with access to and use of the network.

- Establish the necessary conditions to ensure investment in the support infrastructure required by the digital economy and its contents.

- Ensure the development of human resources compatible with the requirements of the new digital economy.

- Become a catalyst in the use of the Internet, by modernizing the public apparatus.

- Coordinate the actions of the public and private sectors and of non-governmental organizations in order to ensure an efficient effort and take advantage of the synergies among these actions.

Chile was the first Latin American country to introduce the Internet: in January 1992, the first connection was made, in the university sphere. In 1998, in view of the general perception that although the country had achieved some important successes in telecommunications, its performance in terms of the Internet was weaker than that of other countries in the region, a Presidential commission was formed to identify actions to advance further in use of the Internet in Chile. Later, the administration that took office in March 2000 assigned high priority in the public policy agenda to the issue of access to information technologies and the Internet. In his annual speech to Parliament in May of that same year, ${ }^{1}$ the President of the Republic himself said that "Chile must take the lead among countries using information technologies, especially the Internet, as the engine driving new progress: progress based on companies' flexibility and not their size, on people's intelligence and not geographic proximity, on cooperation and not antagonism". To apply this guideline and give

\footnotetext{
1 For the complete speech, in Spanish, see http:// www.presidencia.cl/cuenta/index.htm.
} 
continuity to previously created commissions, the Commission on New Information and Communications Technologies was formed. This multidisciplinary, intergovernmental entity includes representatives of several ministries and public bodies empowered to deal with new information and communications technologies, and its mission is to ensure the development of these new technologies in Chile.

This article analyses the policies for developing the necessary infrastructure for the integration of Chile and all its citizens into the information society and evaluates the progress made in this direction. It is organized in three sections plus the present Introduction. Section II provides a simple model for conceptualizing policies for developing support infrastructure for the digital economy and identifies the basic elements that should be taken into account in them. Section III examines and evaluates the main policy measures recently applied by Chile in this area. Finally, section IV reviews the main challenges to be met in order to continue to develop infrastructure for access to the digital economy and thus help to place the country among those forming part of the information society.

\section{II}

\section{Support infrastructure for the digital economy}

The new information and communication technologies (ICTs) and the development of the Internet are key elements in the transformation that traditional forms and mechanisms for the exchange of information are currently undergoing: a transformation which has expanded to include exchanges of goods and services, giving rise to the terms "digital economy" or "new economy".

The concept of the digital economy mainly refers to the replacement of mechanisms for commercial transactions. The way such transactions are carried out has undergone substantial changes over time, each permitting significant reductions in transaction costs. The systems used have progressed from barter to the use of money, and from money in its different forms to exchanges in virtual space through devices connected to the Internet, making it possible to avoid the transaction costs associated with intermediation. The new economy does not involve disappearance of the traditional economy: only the market changes, with suppliers and purchasers meeting in a virtual space to exchange goods and services generated in the traditional economy.

There are two basic requirements for the success of network-based transactions:

i) Infrastructure: There must be an infrastructure to transmit information, making possible an electronic meeting between suppliers and purchasers; an infrastructure providing the necessary means for agreements to be accepted by the parties involved; and an infrastructure for transporting the electronically traded goods from the supplier to the purchaser.

ii) Content: The information needed for suppliers and purchasers to be fully aware of the terms of the transaction must also be available.

The absence of or limitations to one of these two components will inhibit the success of network-based transactions. It is therefore essential to ensure the harmonic development of both. ${ }^{2}$

The concept of the information infrastructure is illustrated in figure 1, which shows the supply of content offered by the public and private sectors, along with the demand for goods, services or information provided by both sectors. For electronic transactions to take place, a support infrastructure is necessary to facilitate interaction between suppliers and purchasers, thus making possible transactions in the digital economy.

The concept of a support infrastructure for the digital economy includes the whole set of elements necessary to guarantee the success of transactions across

\footnotetext{
${ }^{2}$ One of the central elements in the diagnosis made in 1998 by the Presidential Commission on New Information and Communications Technologies was the identification of a vicious circle between these two components. The commission found that on the one hand the limited development of infrastructure and lack of interest in operating across networks arose from the lack of content, while on the other hand the lack of content was due to the low penetration of Internet in households and companies. This diagnosis permitted the identification and implementation of significant projects that helped to break this vicious circle, among them, the incorporation of the State itself into the network.
} 
FIGURE 1

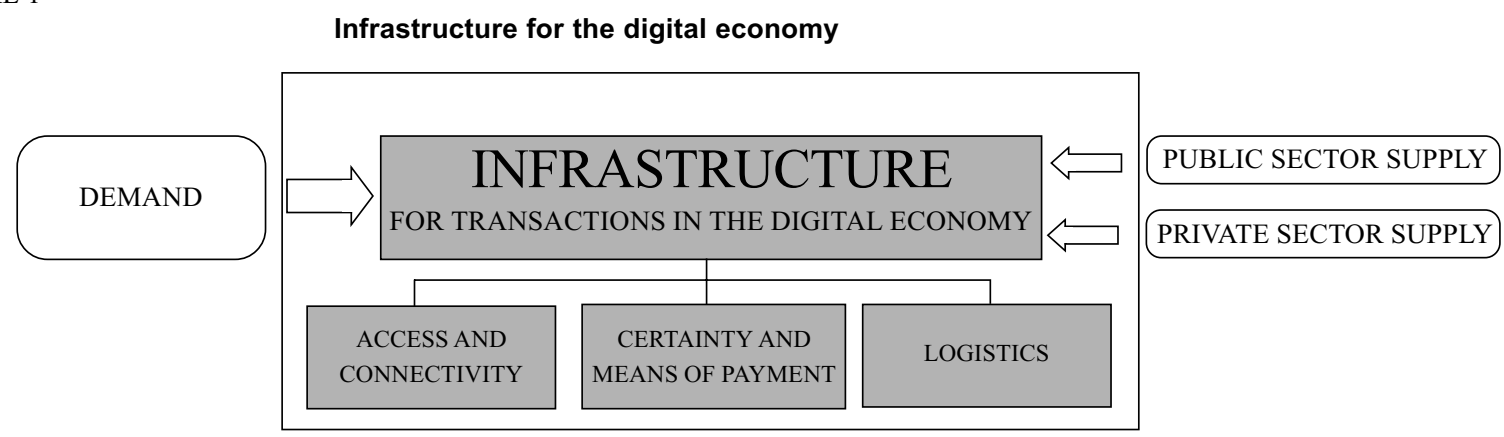

information networks. The three basic elements are: access infrastructure, means of payment and certainty, and distribution infrastructure. With the Internet and the advent of highly competitive, globalized markets, if any of these three elements do not operate promptly and well, opportunities to create added value at the country level can be frustrated. The existence of an adequate supply and demand for goods and services in this virtual market place is also essential, so that a number of measures need to be taken to maximize the potential benefits of these new technologies.

Figure 1 shows how to order policies for encouraging trade through digital media. Several measures can be identified in this respect, involving:

- Strengthening the demand for goods and services traded over the net.

- Developing the access infrastructure.

- Developing the infrastructure designed to provide the means of payment and the corresponding certainty.

- Developing logistical infrastructure.

- Strengthening the supply of goods and services traded on the net.

\section{Strengthening demand for goods and services traded over the net}

A variety of measures can be applied to develop Internet-related capabilities. They involve not only mastering the devices connected to the Internet, but also strengthening English language skills, since today around $78 \%$ of websites and $96 \%$ of e-commerce sites use English. Moreover, to make the Internet more attractive than traditional methods for exchanging information, different incentives can be established, such as tax exemptions for electronic commerce ${ }^{3}$ or

${ }^{3}$ Such as those recently applied in the United States through Law HR 1054 measures to simplify or expedite administrative procedures. $^{4}$

\section{Developing the access infrastructure}

The access infrastructure consists of the telecommunications media and other devices needed to gain access to or connect to networks and to transmit information in such a way as to permit two-way electronic communication among the actors generating the information and its users.

All policies designed to encourage the development of telecommunications networks and devices to permit non-exclusive, efficient and competitive Internet access and data transmission belong to the area of the access infrastructure. It therefore involves the application of regulatory and policy measures that promote the rapid absorption of new technologies and competition in the telecommunications market, thus making Internet access cheaper, as well as policies for creating infrastructure to serve vulnerable or isolated sectors.

\section{Developing infrastructure to ensure certainty and security}

An essential element in any transaction is money, that is to say, the means of payment accepted by the parties involved. Basic requirements for this acceptance include the security of the means of payment employed and certification of transactions. Similarly, security regarding the agents involved in a transaction is essential, and this involves their digital identity, along with trust in the inviolability of the private data transmitted across the network.

In this sphere, conditions must be generated that guarantee protection of the digital identity, by providing

\footnotetext{
${ }^{4}$ Such as those applied in Chile and Brazil for tax declarations.
} 
full security for the information moving through networks by means of systems of authentication, certification, privacy and security to deal with any information technology incidents.

\section{Developing the logistical infrastructure}

This area of infrastructure includes policies to guarantee the timely and efficient delivery of goods or services acquired electronically. Measures to be applied in this respect include the creation of "back office" logistical systems that minimize dispatch times through efficient inventory management and proper organization of the distribution industry to ensure the timely and informed delivery of goods to users.

\section{Strengthening the supply of goods and services}

The potential benefits of Internet use depend very much on the network content being of interest to users; consequently, the relevant policies must be designed to stimulate this content. The public sector can become a catalyst for the use of the Internet by stimulating access to public services through the Internet.

In this respect, the main challenge facing this sector is to move the State into the virtual arena so as to bring public services closer to people, while for the private sector the challenge is to develop suitable content on the network, especially by aiding small and mediumsized firms, which often find it more difficult to participate in a system based on virtual supply.

\section{III}

\section{Information infrastructure development policies in Chile}

This section describes the main policies applied in Chile to stimulate the development of support infrastructure for the digital economy and evaluates the country's status in terms of access and connectivity infrastructure.

The Chilean strategy has been to minimize the regulations applied to the industry, to promote more Internet connections, and to develop close privatepublic cooperation in the various bodies engaged in the preparation of measures to favour development of the Internet. Right from the start, the Presidential commission on new information and communications technologies began to work closely with the private sector, which was considered to be a leading actor in the country's integration into the information society. Later, in May 2001, the Public-Private Alliance was formed. This body, coordinated by the public sector ${ }^{5}$ and made up of companies from the telecommunications and information technology, financial, transportation and postal sectors, was organized to design and establish instruments and projects to encourage the development of infrastructure for access, security and certainty, and distribution.

\footnotetext{
${ }^{5}$ Specifically, by the Special Information Infrastructure Unit created by the SUBTEL (Department of Telecommunications). See (in Spanish) www.chilefuturo.cl.
}

In this same sense, the government has given high priority to private sector participation in the development of the Internet, by organizing several missions, led by the President of Chile and made up of ministers and leading private sector actors, to establish contacts between Chile and key centres of the technology and information industry. These included, for example, the missions to Silicon Valley and Sweden in 2001. Results from these missions include the creation of the Fundación País Digital (Foundation for a Digital Country), a private sector initiative; the startup of a project to create a technology park in Valparaíso; and above all, consensus about the importance of a joint effort to position the country in terms of the new technologies.

A description of the main policies applied in the different areas of information infrastructure in Chile follows, with examples from specific programmes.

\section{Strengthening demand for goods and services traded on the network}

The policies in this field are aimed primarily at training human resources in efficient use of Internet. The demand for information infrastructure is closely tied to the quality and relevance of the contents available 
on the network. Thus, the experience with community "telecentres" indicates that a key element in their success and sustainability is the creation of local content interesting to local people, whose greater or lesser mastery of the computer is a decisive factor in the use of these telecentres. Training has proved to have a direct impact on boosting demand for Internet navigation hours.

In terms of human resource training, several initiatives to reinforce demand for these technologies have been implemented. In the public sector, a training programme in information technologies has been set up for public employees throughout the country; a technology transfer laboratory has likewise been established; and the modification of the curricula of technical institutes to deal with the new requirements associated with information infrastructure is being studied (these institutes receive $40 \%$ of all secondary school students).

Likewise, at the level of small and medium-sized firms, an Internet training programme for companies has been created (www.corfo.cl). This programme seeks to make businessmen see the Internet as a means of improving their competitiveness, expanding markets and making possible new business opportunities. It is designed to train people with different levels of needs for Internet skills, in accordance with the stage reached by the companies concerned in the process of absorption of technologies.

\section{Development of a non-exclusive access infrastructure}

The access infrastructure is that which provides users with access both to the devices necessary to establish communication and to the networks giving access to the basic connectivity infrastructure for data transmission.

a) Access to devices for digital information exchange

Universal access to information technologies is a priority policy objective for reducing the so-called digital divide. According to information up to November 2000 , in that year $16.9 \%$ of Chilean households had a computer and $8.3 \%$ were connected to the Internet. In terms of numbers of people, the figures were better: $29.6 \%$ and $15.9 \%$ of the population, respectively, thus indicating that people have access to computers and the Internet in places other than their homes, as well as through some specific community programmes.
The relatively low rate of household access to the Internet largely reflects the fact that the main medium used is the personal computer, whose high cost constitutes a significant entry barrier. While technological development will introduce new means for accessing the Internet at higher speeds, such as digital television and third generation mobile services, it is necessary to improve access to terminals through specific support programmes.

In late 2001, the private sector started to install public telephones especially designed to send e-mails and messages to cellular telephones at prices accessible to users, which will contribute significantly to more widespread use of the Internet. Similarly, the market is generating solutions that permit Internet access through infocentres.

For its part, the public sector has implemented several measures to promote access to computers, which may be divided into measures of an individual nature and those at the community level.

Among the possible measures to promote individual access to Internet connection devices are subsidies for the purchase of equipment and targeted credit policies. Chile has opted for the second alternative, establishing a programme of soft loans for groups of users with common interests, in this case school teachers and small and medium-sized firms. Unlike other countries, no moves have been made to establish special programmes for improving Internet access by providing lower-cost equipment.

The national Production Development Corporation (CORFO) and the state-owned bank BancoEstado have opened lines of credit to allow micro- and small firms to purchase computer equipment and receive training in Internet use.

To this end, BancoEstado (www.bancoestado.cl) offers two lines of credit to small and medium-sized firms: one called Easy PC Credit, to finance the purchase of a computer, aimed at micro- or small businesses which are formally established and have been in existence for at least one year; and a PC Internet credit scheme to finance the purchase of computer equipment for all kinds of educational establishments, whether State-subsidized or private schools, to help them to set up computer classrooms and obtain equipment for carrying out the school's administrative tasks.

Similarly, in 2001 CORFO set up a programme to provide 10,000 computer sets (equipment and services) for small businesses and teachers, with preferential financing. This programme was repeated at the end of that year, providing the same number of computer solutions. 
The policy for community access to telecommunications services has mainly focused on strengthening infrastructure for vulnerable or isolated sectors, through a subsidy for investment in this respect. Thanks to the universal access policy applied in Chile since 1995 , basic telecommunications infrastructure -wired, wireless and satellite networks- has been developed throughout the country, particularly in rural areas, thus providing extensive coverage, ${ }^{6}$ and it is hoped to expand it to include infrastructure providing universal access to the Internet.

Several other initiatives have also been taken to promote community access to information technologies and are already under way.

"Enlaces" Network. In the context of the educational reform programme, in 1993 an experimental project in the field of computers and digital networks was begun in Chile's State-subsidized schools. It is known as the Enlaces (Links) Network, and its purpose is to integrate information technology into the educational system as a resource for teaching and learning, training teachers, and developing relevant content. By 2000, 90\% of Chile's students were in schools with a computer room connected to the Internet (100\% coverage of secondary schools and $50 \%$ of primary schools). In 2001, an educational portal (www.educarchile.cl) was inaugurated to help the community advance in terms of educational content relevant to the formation of human capital.

National Community Infocentre Programme. This programme is a means for the coordination and generation of inter-institutional alliances. It operates through a governmental working group that coordinates public initiatives in this area, creates alliances and designs policies to promote universal community access, in close coordination with nongovernmental initiatives. A national list of infocentres has been prepared (www.gobiernodechile.cl and www.mapas.moptt.cl), which so far lists 184 such centres; this includes 18 infocentres for small and medium-sized firms, which will soon rise to 60 . Similarly, in 2002 the government department responsible for libraries, archives and museums (Dirección de Bibliotecas, Archivos y Museos) was due to set up around 366 infocentres in its premises in

\footnotetext{
6 The Telecommunications Development Fund programme, which started in March 1995, helped to improve the coverage of public telephones to virtually the whole country within five years. Only $3.2 \%$ of households now lack access to telephone service, that is, do not even have access to public telephones.
}

municipalities all over the country: this initiative is being carried out jointly with the Gates Foundation. Among the measures for developing these infocentres throughout the country are projects for the recycling of computers and the establishment of community telecentres.

Computer recycling project for Infocentres. This initiative, begun in 2001 as part of the Public-Private Alliance, aims to create infocentres run by nongovernmental and community organizations, with equipment and services provided by private firms. The State's role is mainly that of management, targeting and selection of the institutions responsible for running the infocentres, along with coordination among the companies and civilian organizations involved. By late 2001 , ten infocentres were up and running, and by the end of 2002 another 100 were due to be established, using recycled elements.

Community Telecentres. This programme, in association with the Telecommunications Development Fund (see www.subtel.cl), seeks to provide local communities with an integrated community solution in terms of telecommunications services, including the Internet. The implementation of this programme, involving competitive grants to subsidize the development of community telecentres, is designed to generate community telecommunications and Internet infrastructure in isolated locations. The subsidy is financed from the general State revenues, so it has no distorting effect on the industry. The allocation of funds is efficient, in that those projects offering the most social benefits compete among themselves and the subsidies go to those applicants who meet the basic requirements but request the lowest amounts. To date, five community telecentres are up and functioning, as part of a pilot project that should develop further in 2002.

\section{b) Basic connectivity infrastructure to access the digital economy}

Chilean telecommunications policy has stimulated a rapid increase in the telecommunications infrastructure, which is of a high standard compared to other countries with similar per capita income. Because of the early market liberalization, ${ }^{7}$ privatization of the main fixed telephone and long-distance companies in the late $1980 \mathrm{~s}$, and the application of a regulatory framework that encourages investment, market competitiveness and universal access, investment in

\footnotetext{
${ }^{7}$ In the early $1980 \mathrm{~s}$.
} 
telecommunications has risen steadily and with it the importance of this sector to the country's economy.

Internet access in Chile has grown strongly since mid-1999, because of the reduction in the price of dialup connections, technological progress that permits higher-speed Internet access -at prices that residential and small business users can afford- and a minimal regulatory framework in a competitive market. ${ }^{8}$ To date, the penetration rate for Internet access is over $20 \%$, thanks to the leap in the number of new broadband connections that became available as from 2001.

Although the basic connectivity infrastructure, understood as the basic Internet access infrastructure, which consists mainly of the public fixed telephone network, has performed well by regional standards, the country still displays a significant deficit compared with developed countries (table 1).

In terms of the organization of the industry, although there have been some substantial advances towards the entry of new operators and the development of new services, the market structure of the sector still shows a significant degree of concentration, particularly with regard to access to the "last mile", where the dominant operator still controls about $80 \%$ of the market. In other services, such as mobile telephone service, long distance and the Internet, although there are many operators $(4,13$ and 42 respectively) the market still tends to be controlled primarily by two or three firms, whose business is vertically integrated at every level.

Access to the digital economy requires access and connectivity infrastructure at three levels:

i) International connectivity. For the country to be fully integrated into global communications systems it needs an infrastructure connected to systems abroad via international links to form part, ultimately, of the global network of networks, thus placing the opportunities that exist elsewhere in the world within the grasp of Chilean individuals and companies.

In early 2001, two rings of underwater cable offering continental coverage and capable of processing 2.56 terabytes per second came into operation, thus connecting the Chilean network to systems operating in the United States and from there to the rest of the world. This represented a quantum leap in terms of international connectivity capacity, eliminating a

\footnotetext{
${ }^{8}$ At the household level, in terms of Internet access infrastructure, in November $200017 \%$ of households had a computer and $8.2 \%$ an Internet connection.
}

TABLE 1

\section{International comparison of telecommunications service coverage, $\mathbf{2 0 0 0}$ \\ (Telephone lines, subscribers and users per 100 inhabitants)}

\begin{tabular}{lccc}
\hline & $\begin{array}{c}\text { Fixed } \\
\text { telephones }\end{array}$ & $\begin{array}{c}\text { Mobile } \\
\text { telephones }\end{array}$ & $\begin{array}{c}\text { Internet } \\
\text { users }\end{array}$ \\
\hline Argentina & 21.3 & 16.3 & 6.8 \\
Brazil & 18.2 & 13.6 & 2.9 \\
Colombia & 16.9 & 5.3 & 2.1 \\
Chile & 22.1 & 22.2 & 16.6 \\
Mexico & 12.5 & 14.2 & 2.7 \\
Peru & 6.4 & 4.8 & 9.7 \\
Uruguay & 27.8 & 13.2 & 11.1 \\
Venezuela & 10.8 & 21.7 & 3.9 \\
United States & 70.0 & 39.8 & 34.7 \\
Spain & 42.1 & 60.9 & 13.3 \\
Finland & 55.0 & 72.0 & 37.2 \\
England & 58.8 & 72.7 & 25.8 \\
Italy & 47.4 & 73.7 & 23.0 \\
Sweden & 68.2 & 71.7 & 45.6 \\
\hline
\end{tabular}

Source: International Telecommunication Union (ITU) and SUBTEL.

significant barrier to the development of information technologies in Chile.

ii) National connectivity (backbone). Networks are needed to connect communities at the local and national levels, at speeds that satisfy the demands of the country's economic and social development. These networks constitute the system's backbone.

In terms of national connectivity, the Internet access infrastructure can be seen as a trunk network fed by multiple access networks, with the public telephone network being the most used today. The trunk network consists primarily of fibre optic networks that provide connectivity at the national and international levels and meet capacity needs without restrictions.

In Chile, the region between Arica and Puerto Montt has three fibre optic networks at the national level, apart from local networks in the country's main cities. As a result, the supply of services is sufficient and competitive in most of the country, although the southernmost region remains unserved. There, the State's participation on a subsidiary basis is being studied.

iii) Local connectivity or end-user access. It is necessary to have means of transmission through which it is possible to reach digital nodes -mainly switches or routers that can channel digital communications to users or contents located both inside the country and abroad. 
As regards local connectivity, that is to say, networks for accessing the Internet that connect users to the national connectivity system, the public telephone network is the most significant component. ${ }^{9}$ More than $53 \%$ of Chilean households have telephone service, mostly in urban areas and higher income sectors. Most of this network uses traditional copper cables; the rest uses technologies based on TV cable networks and wireless technologies (wireless local loop (WLL), or satellites in rural areas).

A central element of telecommunications policy in recent years has been the stimulation of competition in the "last mile" access market. With the advent of digital signals, technological differences between networks have become increasingly irrelevant: a phenomenon known as convergence. Network technologies are incorporating the IP protocol as the support standard for almost all known and developing services, placing these within reach of individuals and companies, whoever the operator and whatever the type of network. Convergence of media thus offers the chance to deepen competition as a necessary condition for the proper development of a telecommunications network infrastructure offering users more and better local connection alternatives.

At the national level, new technologies are expected to be introduced that will contribute to broadband access and promote competition in the end-user access market. Recently, an experiment in the introduction of Power Line Communication (PLC) technology began, which can provide access to the Internet backbone using household power lines. Similarly, while awaiting the arrival of third generation $(3 \mathrm{G})$ service, the mobile telephone industry is working with medium-speed data transmission, referred to generically as $2.5 \mathrm{G}$. Finally, as regards digital television, the country faces some challenges in terms of defining the technical standard for terrestrial digital television and designing a model for the transition from analogue television: nonexclusive access to this technology must be guaranteed, along with the creation of conditions that will allow television channels to position themselves more competitively in the telecommunications sector, within a context of convergence. ${ }^{10}$

\footnotetext{
${ }^{9}$ In Chile, $100 \%$ of the dial-up and transmission networks installed for local telephone service have been digital since 1993, so that Chile has had a suitable infrastructure for data transmission since the early 1990s.

${ }^{10}$ See subtel (2000).
}

The private sector is responsible for introducing the new technologies in a timely and efficient manner, whether by using the existing networks or creating new ones, while the task of the State is to improve and adapt the regulations to ensure the prompt incorporation of new technologies, as well as simplifying the procedures for authorizations and watching over market behaviour to ensure healthy competition.

\section{Development of an infrastructure providing certainty and security}

A key factor for the development of the digital economy is the availability of recognized, secure and low-cost means of payment. The very nature of electronic commerce, which allows the supplier and the consumer to be located in different countries with different legal systems, makes it necessary to have well-known and accepted means of payment. This requires a broadly accepted set of rules and appropriate institutions that guarantee the efficiency of certification procedures, can referee electronic transactions and commercial information, and protect users from abuse or deception.

Any deficiency in trust-related conditions, understood as those relating to network security, means of payment, certification procedures and guaranteed privacy, can become a barrier to electronic commerce -especially when providing services across networksand thus endanger the competitiveness of the digital economy and increase country risk in the field of electronic operations.

People's evaluation and use of information networks depend on the degree of certainty that these can offer. ${ }^{11}$ In other words, the use of the network is extremely sensitive to users' perceptions that it offers suitable conditions to guarantee the security and privacy of the information transmitted across it. Thus, a policy that helps to strengthen the perception of network security, privacy, integrity and authenticity of communications and information, along with certainty in payment systems, stimulates the creation of added value through the network.

In Chile, two bodies have appeared that provide certification services, and they could become a basic instrument for generating trust in business-to-consumer (B2C) exchanges. Furthermore, the system of digital signatures was recently approved, which will help to

\footnotetext{
${ }^{11}$ A study in the United States indicates that in 2001, 42\% of fraud reports referred to theft of credit card or personal data over the Internet.
} 
overcome some legal restrictions that limit electronic exchanges.

As regards the means of payment, Chile has made progress in arranging for the traditional payment card system to cover monetary transactions over the network throughout the country. In order to achieve mass use of these systems for transferring money and speed up access to the digital economy, however, the country must resolve the issue of how to devise means to enable the lower-income sectors to make payments over the Internet, because they have no access to traditional financial instruments. Another important challenge in this area is how to deal with its very high level of concentration in the hands of Transbank, which is the company that handles all the traditional financial credit cards. In this respect, the big department stores have managed to compete to a significant extent in the credit market using their own credit cards.

With respect to incidents involving computer communications, measures should be taken to strengthen the availability of intelligent devices for reducing the possibility of attacks that place information integrity and people's privacy at risk. Likewise, it is vital to form highly skilled teams to take vigorous action in the event of any threat to the security of information exchanges.

Among the main initiatives taken by the private sector and above all the public sector with regard to the certainty and security infrastructure are the following.

Privacy. The Confiare ("I will trust") project, sponsored by the National Chamber of Commerce and a number of companies and associations involved with information technologies, also with participation by some public-sector institutions, is now under way. This non-profit initiative aims to build trust between Internet users and providers regarding the use made of information, by certifying member sites that meet certain minimum standards of privacy.

Basic reports on Internet security for users and recommendations regarding safe practices. In the sphere of user education, security newsletters have been prepared for different types of Internet users (such as residential users, small and medium-sized firms, etc.) and others for parents, children and adolescents who surf the Net. These teach some basic security measures for Internet use. A report has also been prepared which identifies a number of computer security issues and makes a series of relevant recommendations. These security reports may be found on the SUBTEL website as well as on the portals of the main Internet service providers (ISP) in Chile.
Law on electronic signatures. Electronic signatures have been valid in the public sector since 1999. The recent approval of the law on such signatures in January 2002, which established the equivalency of printed and electronic documents and recognizes the validity and value as proof of minutes and contracts signed by electronic means, will help to build trust and reaffirm the legal and technological security of electronic transactions over the Internet. By mid-2002, relevant regulations were due to come into effect that would establish an accreditation and certification system for private firms, government bodies, the judicial system and the legislature.

Development of information security policies within the public sector. This inter-ministerial initiative is designed to establish a general information security policy within the public administration and create the methodological tools for its implementation, as well as information risk management procedures and auditing mechanisms. A cooperation network against cyber-crime has been set up and is developing procedures and agreements involving the criminal investigation department of the police force, the Ministry of Justice, the Office of the Under-Secretary of Telecommunications, Internet service providers and security companies, to coordinate reports of offences and the investigation and punishment of information-related crime.

\section{Development of the logistics infrastructure}

The existence of efficient distribution mechanisms is an essential requirement for electronic commerce. This distribution involves not only the timely delivery of goods purchased on-line, but also the existence of a logistical system that guarantees the availability of the goods being purchased and their timely dispatch.

In order for distribution to be efficient, the system must supply quality services, that is, delivery must be timely, the merchandise must arrive in optimum condition, the product must be traceable during transport, and so on. Ideally, a range of alternative services should be available to provide different pricequality combinations, so that users can choose the combination best suited to their needs and limitations. This means that competition must be encouraged, along with the transparency of the delivery service market.

The courier industry must adjust to the needs of electronic commerce, thus requiring a review of dispatch procedures and reorganization of the systems and infrastructure for transportation, storage and distribution, along with on-line information systems. 
The courier industry in Chile has advanced significantly, with the development of new services to adjust to the needs of electronic commerce. On one hand, already established private companies, such as LanCourier (www.lancourier.com) have adapted to these demands by offering new services in distribution and logistics (for example, on-line tracking and just-in-time delivery) and providing both transparency and lower costs. On the other, new companies have appeared that aspire to meet international standards, such as ChilePost (www.chilepost.cl), along with other international operators, which contributes to the development of more competitive markets.

In the public sector, the Chilean postal service (Empresa Correos de Chile) faces major challenges in modernizing and adjusting to electronic trade, because it must compete with operators applying very high quality standards yet it still displays some weaknesses as regards simplifying procedures and developing customer-oriented services in electronic commerce. In countries where the main postal system remains Staterun, it plays an important role because as it is present throughout the country, it constitutes the only distribution option for most of the national territory, which is fundamental for bringing e-commerce to the masses. Furthermore, its extensive infrastructure opens the way for solutions designed to provide mass Internet access, particularly in more isolated areas.

Finally, in order to adjust logistics to the demands of these new technologies, a review must be made of the instruments aimed at furthering the incorporation of new management practices based on information and telecommunications technology, particularly in terms of back office procedures in small and medium-sized firms.

\section{Strengthening the supply of goods and services}

The policy of strengthening the supply of goods and services has mainly been associated with the creation of public sector content in order to act as a catalyst for encouraging Internet use by the general population. But the private sector has also made a significant effort and has recently been very active in this field. Thus, from March 2000 to March 2001, the number of virtual stores rose from 57 to 481 and the number of B2C products went up from 37,000 to $340,000,{ }^{12}$ while the volume traded ${ }^{13}$ doubled.

\footnotetext{
12 See Santiago Chamber of Commerce (2001).

13 In 2001, B2C commerce reached US\$ 65 million, while B2B (business to business) commerce reached US\$ 900 million.
}

In terms of content, the public sector has made rapid progress in pursuance of a decision to move towards electronic government by placing several public services on line. A particularly notable effort was that of the internal revenue service (SII), which has allowed people to file their tax returns via Internet since 1999, turning it into a world leader in its field. For the 2001 tax year, 788,645 tax returns were filed by Internet, representing $41.6 \%$ of the total number of taxpayers. Similarly, various procedures can be carried out over the Internet in other public services, thus saving time and paperwork: these include the payment of social security contributions on line in the Instituto de Normalización Previsional (INP) (www.inp.cl) and the issue of various certificates from the national registry of births, marriages and deaths (www.registrocivil.cl). Various portals designed to bring the State closer to citizens are also currently available or in preparation, some of which are described briefly below.

\section{a) Information on public sector procurement (compraschile.cl)}

This system provides information on the goods and services required by the Chilean government and was designed to distribute and maintain information on the Internet about procurement operations, with each procedure duly documented on-line in a transparent fashion. On this site, State institutions publish their needs for goods and services, so that any user can find out about them and thus become a potential supplier.

b) One-stop "window" for government services

This project attempts to allow citizens requiring some service offered by the public sector to gain access to them from a single entry point where the institutions and procedures involved are presented in a transparent manner. The purpose of this "single window" is to provide less expensive access to State services, and thus streamline and facilitate government-related procedures so as to satisfy citizens' needs and allow them to comply with their obligations or request authorizations, reducing the time and cost of these processes for both the State and users.

In this context of modernization of the State, the web site www.tramitefacil.gov.cl was set up to provide information on the different procedures that people must follow in different public offices and allow them to carry out these formalities directly on line. This website constitutes a single window (on-line) for applications from citizens: at present, 38 procedures can be carried out at this site and information obtained on another 700 . 
Another programme functioning as a one-stop online service shop is the website www.sitioempresa.cl which provides services for companies and allows them to enter the appropriate websites for different formalities. It includes a specially designed website for those who wish to form a company and need to know what the procedures are in order to establish it and enter the market.

\section{c) Use of information technologies within the State sector}

This project aims to introduce the use of new ICT technologies inside and among public bodies so as to improve their management efficiency and effectiveness by saving time and resources over their documentation requirements. To do so, the project provides for the identification of recurring internal procedures in the different bodies and their redesign to take advantage of these new technologies.

Similarly, it seeks to expand the use of ICT in the State sector beyond the basic levels of e-mail and web pages and to use it to support internal management, by providing shared technical support for smaller institutions so they can make the most of economies of scale and establish more expedite communications mechanisms by using a common electronic identification system shared throughout the central government.

\section{d) Infrastructure for public services}

The government is studying the introduction of a concession system for the digital infrastructure, whereby the State could entrust a private agent with the construction of the physical infrastructure needed to house its electronic platform for public services and then go on to entrust the private sector with both the management of the information associated with this public good and the distribution of the products required by individuals.

\section{e) Other initiatives for improving public sector Internet content}

A number of public bodies are engaged in spontaneous initiatives to improve Internet content and streamline service procedures. These include on-line procedures for telecommunications concessions, set up in late 2001 by the Department of Telecommunications, and the Ministry of Education's decision that as from 2002 university students must apply for government grants solely via the Internet, for which purpose it created 300 infocentres with the necessary equipment to ensure that all applicants have access to this mechanism.

\section{IV}

\section{Policy challenges for the information infrastructure}

The information infrastructure has made substantial progress in recent years, as a result of a decisive commitment to carry the country forward into the information society. Key elements in this have been the determination and effort displayed by both the public and private sectors. Nonetheless, the country is still in the midst of building the support infrastructure necessary for the digital economy. Consequently, there are many challenges that still need to be faced by both sectors in the coming years if they are to achieve the widespread use of the Internet as a tool for work, trade, leisure, education and social integration.

\section{Efficient development of the telecommunications infrastructure}

In the context of globalization, sustained and sustainable economic growth will be increasingly linked to the development of the information infrastructure, which must necessarily be combined with the other fundamental productive factors in a strategy of growth with equity.

The efficient development of the telecommunications infrastructure is, in turn, linked to the existence of competitive markets. When media are converging with each other and a single service can be transmitted along networks using different technologies, while different networks can transmit the same services, it is essential at least to guarantee competition among networks.

Since the early 1980 s, and increasingly since the 1990s, Chile's telecommunications policy has sought to deepen competition as a necessary condition for achieving a suitable infrastructure for telecommunications networks, which is a basic requirement for gaining access to the information society. In this sense, 
market mechanisms must be expanded, the infrastructure and high-quality services must be extended to low-income sectors that are still without services, ${ }^{14}$ and progress must be made towards integrating new technologies in the "last mile" that will make it possible to move closer to the deregulation of this segment. Public intervention should be restricted solely to technical regulation, the correction of distortions and the application of policies of a subsidiary nature. The same principle applies to the other segments of this industry, in which the development of technology and services demands timely allocation of the electromagnetic spectrum and the establishment of regulations compatible with a context of convergence.

Improving and expanding mechanisms to reduce anti-competitive practices, together with the elimination of barriers to the entry of new companies and obstacles to the exit of dissatisfied users can help to promote competition within a single network. Other valuable mechanisms include those for disaggregating networks, making telephone numbers portable, and monitoring and severely punishing anti-competitive behaviour. Tariff regulations and a policy of allocating the electromagnetic spectrum in such a way as to promote the development of services in competitive markets will also help to ensure proper allocation of resources to maximize social benefits.

In order to encourage competition among networks, new technologies must continue to be introduced, such as wireless networks, power line communication and digital television. Other challenges include the need to: expedite the introduction of new concessions, which will require the timely adoption of technical standards and invitations to compete, when necessary; simplify the procedures for granting concessions, through a single license; and rapidly give rulings on administrative complaints designed to block new players from entering the arena.

\section{Equality of access to the Internet}

Reducing the differences in access to the Internet, be they the result of territorial-, gender-, ethnic- or agerelated factors, is essential in order to ensure the nonexclusive development of the information infrastructure. To achieve this, an evaluation must be made of the policies on access to this infrastructure, as

\footnotetext{
14 This means facilitating the application of mechanisms like prepayment systems and others which have facilitated the mass use of mobile telephony.
}

well as considering targeted policies aimed at providing infrastructure for the most vulnerable and/or marginalized sectors. The information infrastructure provides these sectors with a powerful instrument for gaining access to better opportunities and a better quality of life. In this respect, residence in rural or isolated areas, physical disability or urban poverty must cease to be factors limiting the development of these communities.

One of the challenges still pending is the need to progress in the building of a national network of infocentres covering isolated rural areas and lowerincome urban areas, as well as establishing the regulatory instruments needed to promote the expansion of telephone service coverage to households that are still without it.

Expanding the capacity and coverage of the telecommunications infrastructure in a territorially balanced fashion is crucial for non-exclusive integration into the Internet. In order to promote territorial integration, consideration must be given to the introduction of new instruments that will help to extend the basic and broadband infrastructure to distant locations, and above all, to the extension of the fibre optic network to the extreme south of the country, thus completing a continental broadband trunk network.

\section{Eliminating barriers to Internet use}

Factors which hinder greater use of the new information and telecommunications technologies and inhibit network applications, particularly those involved in electronic commerce and other business activities, must be eliminated. Among the most urgent tasks in this area is the continued generation of instruments to encourage e-commerce and make it more secure. Moreover, the distribution industry must be urged to adjust to the standards demanded in more developed countries.

\section{The growing presence of the State on the networks}

The State's involvement in the networks represents a catalyst for the digital economy, while at the same time improving citizens' quality of life and bringing public services closer to users. Although there has been considerable progress in designing on-line governmental programmes, those still underway must be completed and the population educated on how to use them. Likewise, the country must continue to promote the development of private sector content. 


\section{Strengthening institutions in a context of media convergence}

Because of the importance of telecommunications and information technologies to economic development, institutions must be adapted so they can more quickly absorb new technologies and information. To do so, the harmonic development of regulations for converging services must be promoted and further progress must be made towards the integration of telecommunications, information technologies, and science and technology within a single ministry. This would make it possible to replace the current multi-ministry approach, which reduces the opportunities for synergies among converging sectors and limits the efficiency of policies based on the principle of institutions focusing on the development of sectoral infrastructure. One challenge still pending is to create a Superintendency of Telecommunications which will allow enforcement activities to be separated from those aimed at furthering sectoral policies.

\section{Participation in building infrastructure}

Private sector participation is a central element in the construction of the information infrastructure, because the telecommunications sector has steadily lost its character of a traditional public service ${ }^{15}$ and must progress towards a more self-regulatory approach. In this sphere, the public sector must increasingly play the role of facilitator, helping to secure increased investment.

Finally, another challenge is to strengthen citizens' participation, to use the Internet as a tool for participation, to stimulate the development of content that will help to create better-informed citizens, and to improve markets by helping citizens to exert their rights as consumers.

(Original: Spanish)

\footnotetext{
15 For an analysis of the nature of telecommunications services, see Cominetti and Pérez (2001).
}

\section{Bibliography}

Cominetti, R. and E. Pérez (2001): Sector telecomunicaciones: modelos de institucionalidad alternativos, December, unpublished.

Santiago Chamber of Commerce (2001): La economía digital en Chile, 2001, www.ccs.cl.

SubTel (Department of Telecommunications) (2000): Propuesta de un marco normativo para la introducción de la televisión digital terrestre en Chile, Santiago, Chile, February, www.subtel.cl.

(2001): Informe estadístico, No. 3, Santiago, Chile, December.

(2002): Informe estadístico, No. 4, Santiago, Chile,

INFRASTRUCTURE TO SUPPORT THE DIGITAL ECONOMY IN CHILE • ROSSELLA COMINETTI C. 